African Journal for Physical, Health Education,

Recreation and Dance (AJPHERD)

Vol. 12, No. 4 (December) 2006, pp. 394-402.

\section{PERCEIVED CONSTRAINTS TO PHYSICAL ACTIVITY AMONG STUDENTS AT PARAMEDICAL INSTITUTIONS IN UGANDA}

\section{E. Nizeyimana and J.S. Phillips}

\section{ABSTRACT \\ In the developing world, particularly Sub- Saharan Africa, physical inactivity along with tobacco use, poor diet and nutrition are increasingly parts of today's lifestyle. The aim of this study was to assess the levels of physical activity, and to investigate perceived constraints to physical activity among students in paramedical institutions in Uganda. A self- administered questionnaire adapted from the literature was administered to 400 students. The results indicated that $59 \%$ of participants were classified as physically active and $41 \%$ as sedentary. Males were significantly more active than females. For male participants, "lack of the right equipment to exercise" and "wanting to do other things in their free time" were perceived as the major constraints to physical activity. For female participants, "lack of motivation" and "tiredness after exercise" were perceived as the major constraints to physical activity. Thus, recommendations to eliminate these specific constraints and increase physical activity of paramedical institution students are offered. The findings of this study demonstrate that there is an influence of socio-demographic characteristics on participation in physical activity and perceived constraints to physical activity. The findings further indicate the need of health promotion intervention aiming at promoting physical activity among paramedical institution students in Uganda.}

Key words: Physical activity, students, young adults, perceived constraints, sedentary lifestyle, Uganda.

E. Nizeyimana, M.Sc Physiotherapy

J.S Phillips, $P h D$. Physiotherapy

Department of Physiotherapy

University of the Western Cape

Private Bag X17

Bellville

7535

South Africa

Email:jphillips@uwc.ac.za

\section{INTRODUCTION}

Sedentary lifestyle or physical inactivity is a major underlying cause of death, disease, and disability (WHO, 2002). In the developing world, particularly SubSaharan Africa, physical inactivity along with tobacco use, poor diet and nutrition are increasingly parts of today's lifestyle. According to Grubbs (2002), health benefits of physical activity depend on being active throughout the lifespan. However, for most people physical activity declines with age and the most rapid decline appear to occur during late adolescence and early adulthood. It has been documented that physical activity is altered during the transition period from high school to university. This may have important acute physical and psychological consequences for college and university students. The decline in physical activity during this period may lead to patterns of inactivity that persists throughout one's university years and beyond (Bray \& Born, 2004).

Identifying constraints to physical activity remains an important goal in health promotion planning program (Tai- Seale, 2003). 
A great variety of physical activity constraints have been identified as lack of time, inconvenience, lack of self-motivation, the belief that exercise is boring or not enjoyable, low self-efficacy, fear of injury, poor selfmanagement skills, lack of social support, and insufficient access to safe places to exercise (King, Blair, Bild, Bishaman, Dubbert, Marcus, Oldridge \& Pafferenbarger, 1992; Tergerson \& King, 2002; WHO, 2002; TaiSeale, 2003; WHO, 2003).

Although there is no specific information about physical activity participation among young adults including students at paramedical institutions in Uganda, there is evidence of physical inactivity among adolescent students. In 2003 a global schoolbased student health survey was conducted in rural Uganda to measure the dietary behaviour, hygiene, unintentional injury and violence, mental health, tobacco use, alcohol and other drug use, sexual behaviour as well as physical activity level among adolescents. The study found that only $11.4 \%$ of students were physically active for a total of at least 60 minutes per day during the past seven days (Twa-Twa, 2003). This study was carried out to assess the levels of physical activity among students at paramedical institutions in Uganda and to investigate their perceived constraints to physical activity.

\section{METHODS}

There are four paramedical institutions in Uganda that train undergraduate students who are between the ages of 18 and 35 years. The study was carried out at two of these institutions. All students registered for full time 2004/2005 academic year in these two paramedical institutions were requested to participate in the study. A stratified random sampling technique was used to select the participants in this study. Four hundred (400) students were selected and informed consent was obtained from the participants. Four hundred (400) structured self-administered questionnaires were distributed to the 8 different schools at the institutions that participated in the study. These schools included: physiotherapy, occupational therapy, dentistry, orthopaedic officers, orthopaedic technology, medical lab technology, pharmacy and school of clinical officers.

The structured self- administered questionnaire was divided into three sections and had close-ended questions. The first section covered socio-demographic information. The second section assessed the physical activity levels of the participants. The questions asked were adapted from the Sub-Saharan Africa Questionnaire developed and validated by Sobngwi, Mbanya, Unwin, Aspray and Alberti (2001). 
The last section assessed perceived constraints to physical activity and was adopted from the questionnaire developed and validated by Tergerson and King (2002). Descriptive and inferential statistics were used to analyse the data with a p-value of 0.05 or less taken to indicate statistical significance.

Three hundred-and-sixty (360) students completed and returned the questionnaires, thus the overall response rate was $90 \%$. Approximately three- quarter of student participants were males $(73.9 \%)$ and onequarter were females (26.1\%). The highest number of participants was in their second year of study (40.0\%) and a few were in their third-year of study (24.7\%). The highest number of participants was drawn from the school of clinical officers (16.4\%) and the smallest number of participants was from the school of occupational therapy $(9.7 \%)$ as illustrated in Table 1.

\section{RESULTS}

Two hundred and thirteen (59\%) of the participants were classified as physically active and 107 (41\%) participants were classified as physically inactive or sedentary as illustrated in Figure 1. The respondents' level of physical activity was determined according to the WHO's guidelines on recommended quality and quantity of physical activity. The WHO recommended that, for an average adult engaging in at least 30 minutes of physical activity of moderate intensity every day or most days of the week would be sufficient to gain health benefits (WHO, 2005).

Male students were significantly more active (66.9\%) compared to their female counterparts $(45.7 \%), \mathrm{X}^{2} 13.136 \quad(\mathrm{p}<0.05)$. No significant difference was found between the participants' current year of study and current participation in physical activity $\left(X^{2} 0.353, \quad p>0.05\right)$. Participants in the physiotherapy department were found to be significantly more likely to be sedentary than those in other departments $\left(\mathrm{X}^{2} 14.998\right.$, $\mathrm{p}<0.05)$.

For male participants lack of the right equipment to exercise (Mean score 2.70; SD 0.96), and wanting to do other things in their freetime (Mean score 2.59; SD 0.89) were identified as the major perceived constraints to physical activity (Table 2). For female participants lack of motivation to exercise (Mean score 2.6; SD 096) and "exercise makes me tired" (Mean score 2.56; SD 0.90) were identified as the major perceived constraints to physical activity (Table 3). 
Table 1: Socio-demographic characteristics of the study sample $(\mathrm{n}=360)$.

\begin{tabular}{|l|l|l|l|}
\hline Variables & & Frequency & Percentages \\
\hline Gender & Males & 266 & 73.9 \\
\hline & Females & 94 & 26.1 \\
\hline Year of Study & $1^{\text {st }}$ year & 127 & 35.3 \\
\hline & 2nd year & 144 & 40.0 \\
\hline & 3rd year & 89 & 24.7 \\
\hline Courses & Clinical Officers & 59 & 16.4 \\
\hline & Physiotherapy & 50 & 13.9 \\
\hline & Technology & 48 & 13.3 \\
\hline & $\begin{array}{l}\text { Orthopaedic } \\
\text { Officers }\end{array}$ & 48 & 13.3 \\
\hline & $\begin{array}{l}\text { Orthopaedic } \\
\text { Technology }\end{array}$ & 43 & 11.9 \\
\hline & Dental & 40 & 11.1 \\
\hline & Pharmacy & 37 & 10.3 \\
\hline & $\begin{array}{l}\text { Occupational } \\
\text { therapy }\end{array}$ & 35 & 9.7 \\
\hline
\end{tabular}

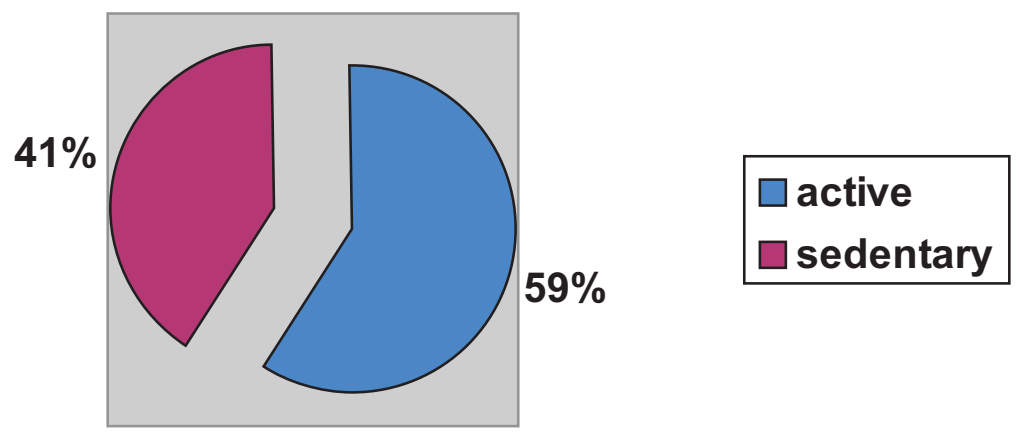

Figure 1: Participation in physical activity (n 360)

Table 2: Males' perceived constraints to physical activity ( $\mathrm{n}=266)$.

\begin{tabular}{|l|l|l|}
\hline Variable statements & Mean Score & $\begin{array}{l}\text { Std. } \\
\text { Deviation }\end{array}$ \\
\hline I do not have a right equipment to exercise & 2.70 & 0.96 \\
\hline I do want to do other things in my free time & 2.59 & 0.89 \\
\hline I do not have transport to the facility & 2.44 & 0.91 \\
\hline I am not motivated & 2.39 & 0.91 \\
\hline Exercise makes me tired & 2.37 & 0.85 \\
\hline I do not have a good place to Exercise & 2.36 & 0.92 \\
\hline I do not have family support & 2.36 & 0.90 \\
\hline I do have too much homework & 2.35 & 0.84 \\
\hline I do not have a good environment to exercise & 2.33 & 0.96 \\
\hline I do have time to exercise & 2.10 & 0.79 \\
\hline I do not have a company to exercise with & 2.12 & 0.84 \\
\hline I think exercise is too hard & 1.87 & 0.69 \\
\hline I am not interested in exercising & 1.79 & 0.75 \\
\hline I do not enjoy exercising & 1.78 & 0.76 \\
\hline I do not know how to exercise & 1.74 & 0.76 \\
\hline I think exercise is not important & 1.62 & 0.72 \\
\hline & & \\
\hline
\end{tabular}


Table 3: Women's perceived constraints to physical activity (n 94).

\begin{tabular}{|l|l|l|}
\hline Variable statements & $\begin{array}{l}\text { Mean } \\
\text { score }\end{array}$ & $\begin{array}{l}\text { Std. } \\
\text { Deviation }\end{array}$ \\
\hline I am not motivated to exercise & 2.62 & 0.96 \\
\hline Exercise makes me tired & 2.56 & 0.90 \\
\hline I want to do other things in my free time & 2.54 & 0.88 \\
\hline I do not have a right equipment to exercise & 2.48 & 1.01 \\
\hline I do not have a good place to exercise & 2.41 & 0.97 \\
\hline I do have too much homework & 2.39 & 0.81 \\
\hline I do not have a good environment to exercise & 2.33 & 0.94 \\
\hline I do not have family support & 2.24 & 1.01 \\
\hline I do not enjoy exercising & 2.16 & 0.92 \\
\hline I do not have time to exercise & 2.13 & 0.89 \\
\hline I do not have transport to facility & 2.13 & 0.88 \\
\hline I am not interested in exercising & 2.07 & 0.95 \\
\hline I do not know how to exercise & 2.03 & 0.90 \\
\hline I think exercise is too hard & 1.98 & 0.82 \\
\hline I do not have company to exercise with & 1.96 & 0.77 \\
\hline I think exercise is not important & 1.57 & 0.71 \\
\hline
\end{tabular}

\section{DISCUSSION}

The levels of physical activity in the current sample is consistent with the findings from the 1995 National College Health Risk Behaviour survey among undergraduate students in the United States of America which showed that $42.2 \%$ of students did not participate in physical activity in the week prior to the survey (Suminski, Petosa, Utter \& Zhang, 2002). However, the findings of the present study differ from those of a similar study recently conducted by Tumusiime (2004), among tertiary institution students in Rwanda, which found that only $28.38 \%$ of the participants were physically active. The discrepancy between results of the present study and those of Tumusiime (2004) could be attributed to the fact that household activities assessed in the present study were not included in Tumusiime's (2004) study. When leisure time physical activity were analysed separately it was found that only $28 \%$ would be classified as physically active.

Identifying constraints to physical activity remains an important goal in planning health promotion programmes. It has been reported that an individual's perceived constraints to exercise are an important determinant of how active he or she becomes. Therefore, understanding those constraints is the first step in removing them (Jones, 2003, Nahas et al., 2003; Tai-Seale, 2003). 
Constraints to physical activity among paramedical institution students in Uganda seem to have some slight differences from those reported in previous studies conducted in the USA and European countries. However, these constraints were similar to those recently identified by tertiary institutions in Rwanda. This may support the argument that constraints to physical activity may be similar or different depending on research settings. In the current study, male participants identified "lack of right equipment to exercise" and "wanting to do other things in their free time" as the most important constraints to physical activity. Tertiary institutions students in Rwanda in the study of Tumusiime (2004) identified the same constraints.

The least important constraints identified by student participants were "I think exercise is not important", "I do not know how to exercise", and "I am not interested in exercising". There was a significant relationship between gender and the above constraints meaning that both male and female participants felt that the above constraints were not the reason why they were not exercising. This gives hope that student participants know the importance of physical activity/exercise, know how to exercise and are interested in staying physically active. However, "wanting to do other things in their free time," identified as the second most important constraint to physical activity could have been the main reason why some of them were not participating in physical activity. Buckworth and Nigg (2004) commented that, "Although college students have specific time constraints related to their academic schedules, they also have considerable discretionary time. It is the choices they make about how to spend this time which influences their level of physical activity and various factors influence these choices". In the current study, time was not a constraint to physical activity, but the choices made by participants on how to spend their free time must have influenced their level of participation in physical activity.

Gender difference on levels of participation in physical activity and perceived constraints to physical activity was noted in the current study. According to the literature, males are generally more active than females (Bronson, Backer, Houseman, Brennan \& Back, 2001). The gender differences observed in the levels of physical activity is probably attributed to each gender group's perceptions of the reasons for participation in physical activity (Huddleston, Mertesdorf \& Araki, 2002). Taiwanese adolescent girls reported lower physical activity, less perceived benefits and more perceived constraints to physical activity yet they had more peer and social support compared to the boys (Tsu-Yin, Nola \& Samar, 2003). 
Similarly, the current study found that male participants were significantly more active compared to female participants.

Males identified "lack of the right equipment" as the most important constraint to physical activity, and females put an emphasis on "lack of motivation" as the most important constraint to physical activity. Tergerson and King (2002) found that peer motivation especially from friends and family members was one of the most common cues to action for adolescent physical activity.

The second most important constraint for female participants was, "exercise makes me tired". According to the literature, men usually report greater levels of total and vigorous activity, whereas women tend to report participating in low- to moderate physical activity (Martin, Morrow, Jackson, Dunn \& Andrea, 2000). The above statement may thus indicate the reason why women in this study identified "exercise makes me tired" as one of their most important constraints to physical activity. However, according to Whaley and Ebbeck (1997), constraints to physical activity should be viewed in a social - psychological manner to indicate internal (intrapersonal) psychological states and external (interpersonal) circumstances. Consequently, "lack of motivation", and "exercise makes me tired" identified as dominant constraints to physical activity among female participants in this study may be intrapersonal rather than interpersonal factors. These may suggest that the major constraints to physical activity among female participants may be personalised rather than seen as a reflection of environmental influence or as a result of external factors. Therefore, it is very important for health workers interested to promote physical activity among female students in paramedical institution to place more emphasis on individual behaviour modification before tackling environmental factors as constraints to physical activity.

Various studies identified "wanting to do other things with one's free time" as a constraint to physical activity (Tergerson \& King, 2002; Tumusiime, 2004). Similarly, in the current study, male participants in particular, identified "wanting to do other thing in their free time" as the second most important constraint to involvement in physical activity. This indicates that there is a need for health promoters to convince students about the benefits of being physically active and design physical activity intervention programmes based on students' interests rather than those of health promoters.

\section{CONCLUSION}

The results of this study indicate that although the majority of the students were found to be physically active, $41 \%$ of the total sample did not participate in moderate to vigorous 
physical activity and were classified as sedentary.

This clearly indicates that there is a need for physical activity promotion among paramedical institution students in Uganda as it has been shown that physical activity improves quality of life in many ways for people of all ages. Research has also shown that regular physical activity has numerous benefits such as reducing the risks of obesity, diabetes mellitus and some forms of cancer. A sedentary lifestyle has further been recognised a risk factor for cardiovascular diseases.

The rates of inactivity in the present study were related to gender differences. Males were significantly more active compared to female counterparts. This suggests that health workers interested in promoting physical activity among paramedical students should consider gender differences when designing exercise programmes. Lack of the right equipment to exercise and wanting to do other things in their free time was the two most important constraints to physical activity for the current sample. However, these constraints slightly differed between genders. Therefore, in order to increase participation in physical activity strategies which focus on activities that help each gender to overcome their constraints to physical activity should be developed. Lack of enjoyment and lack of interest in exercising were not major constraints to physical activity in the Ugandan students. This gives much hope for a successful intervention programme aimed at promoting physical activity in this group.

\section{REFERENCES}

Bray, R.S. \& Heidi, A.B. (2004). Transition to university and vigorous physical activity: implication for health and psychological well-being. Journal of American College Health, 52, 182-187.

Buckwortth, J. \& Nigg, C. (2004). Physical activity, exercise, and sedentary behaviour in college students. Journal of American College Health, 53, 28-34.

Brownson, R.C., Baker, E.A., Houseman, R.A., Brennan, L.K. \& Bacak, S.J. (2001). Environmental and policy determinants of physical activity in the United States. The American Journal of Public Health, 91, 1995-2003.

Grubbs, L. \& Carter, J. (2002). The relationship of perceived benefits and barriers to reported exercise behaviour in collage undergraduates. Family and Community Health, 25, 76-85.

Huddleston, S., Mertesdorf, J. \& Araki, K. (2002). Physical activity behaviour and attitudes toward involvement among Physical Education, health and leisure services pre-professionals. College Student Journal, 36, 555-573.

Jones, K. W. (2003). Understanding barriers to physical activity is a first step to removing them. American Journal of Preventive Medicines, 25, (3Si).

King, A.C., Blair, S.A., Bild, D.E., Dishman, R.K., Dubbert, P.M., Marcus, B.H., Oldridge, N.B. \& Paffenbarger, R.S. (1992). Determinants of physical activity and interventions in adults. Medicine and Science in Sports and Exercise, 24, S22-232.

Martin, S.B., Morrow, J.R., Jackson, A.W., Dunn \& Andrea, L. (2000). Variables related to meeting the CDC/ACSM physical activity guidelines. Medicine and Science in Sports Exercise, 32, 2087-2092.

Nahas, M.V., Goldfine, B. \& Mitchell, A. (2003). Determinants of physical activity in adolescents and young adults: the basis for school and college physical education to promote active lifestyle. Physical Educator, 60, 42-57.

Sobngwi, E., Mbanya, J.C.N., Unwin, N.C., Aspray, T.J. \& Alberti, K.G.M.M. (2001). Development and validation of a questionnaire for the assessment of physical activity in epidemiological studies in sub- 
Saharan Africa. International Epidemiological Association, 30, 1361-1368.

Suminski, R.R., Petosa, Utter, C.A. \& Zhang, J.J. (2002). Physical activity among ethnically diverse college students. Journal of American College Health, 51,4 .

Tai-Seale, T. (2003). Stage of change specific triggers and barriers to moderate physical activity. American journal of Health Behaviour, 27, 219-227.

Tergerson, J. \& King, K. A., (2002). Do perceived cues, benefits, and barriers to physical activity differ between male and female adolescents? Journal of School Health, 72, 374-377.

Tsu-Yin, W., Nola, N. \& Samer, N. (2003). Gender difference in the psychosocial and cognitive correlates of physical activity among Taiwanese adolescents: A structural equation modelling approach. International Journal of Behavioural Medicine, 10, 93-105.

Tumusiime, D.K. (2004). Perceived benefits of, barriers and helpful cues to physical activity among tertiary institutions in Rwanda. Unpublished theses. University of the Western Cape (613.0434).

Twa-Twa (2003). Global School- based health survey Uganda rural. Ministry of Health, Kampala, Uganda. http://www.who.int/school youth health/media/en/gsh s national.pdf. Retrieved 10 August, 2004.

Whaley, D.E. \& Ebbeck, V. (1997). Older adults constraints to participation in structured exercise classes. Journal of Ageing and Physical Activity, 5, 190-212.

WHO (2002). World Health Day 2002: Physical Activity and Youth. http:/www.who.int/archives/world-healthday/factsheets2.en.shtml. Retrieved 10 August, 2004.

WHO (2003). Sedentary lifestyle: A Global Public Problem: physical Activity, Non-Communicable Disease Prevention and Health Promotion. http:/www.who.int/hpr/physactiv/sedentary.lifestyle1.s html . Retrieved 24 April, 2003. 